\title{
Middle-Term Assessment of Cardiovascular Risk Factor Control in a Prospective Cohort of High-risk Patients Treated by Percutaneous Coronary Intervention
}

\author{
Rafael Brolio Pavão1, José Antonio Marin-Neto², Gustavo Caires Novaes ${ }^{3}$, Marcelo Rodrigues Pinto ${ }^{4}$, \\ Geraldo Luiz Figueiredo ${ }^{5}$, Igor Matos Lago ${ }^{6}$, Moysés Oliveira Lima Filho ${ }^{7}$, Daniel Conterno Lemos ${ }^{8}$, \\ Monique Tonani ${ }^{9}$, Cleide Marques Antloga ${ }^{10}$, Luciana Correa de Oliveira ${ }^{11}$, Julio F. M. Marchini ${ }^{12}$
}

\begin{abstract}
Background: Secondary prevention after percutaneous coronary intervention $(\mathrm{PCl})$ is essential to increase event-free survival and consists mainly in risk factor control. We analyzed the secondary prevention of high-risk patients included prospectively in the Sequence Variation in Platelet Aggregation in Response to Clopidogrel and aspirin trial (SPARC). Methods: From December 2009 to February 2011 we enrolled 187 consecutive patients who were submitted to $\mathrm{PCl}$ with stent implantation and were evaluated in outpatient visits at 1,3 , 6 , and 12 months of follow-up for the control of hypertension, dysglycemia, hyperlipidemia and smoking and their respective therapeutic measures. Results: There was a significant increase in the number of patients with controlled hypertension $(29 \%$; $\mathrm{P}=0.02)$, who stopped smoking $(18 \% ; \mathrm{P}=0.003)$, and received statins $(19 \% ; \mathrm{P}<0.0001)$ between the index $\mathrm{PCl}$ and the first follow-up visit. The risk factor control improvement led to a decrease in the mean Framingham risk score (9.9\%; $\mathrm{P}<0.0001)$. During the 12 months follow-up the gains achieved at $\mathrm{PCl}$ admission were maintained for all risk factors. Conclusions: An important effect was observed on the index $\mathrm{PCl}$ admission with increased prescription of risk factor
\end{abstract}

\section{RESUMO}

Avaliação a Médio Prazo do Controle de Fatores de Risco de Doença Cardiovascular em Coorte Prospectiva de Pacientes de Alto Risco Tratados por Intervenção Coronária Percutânea

Introdução: A prevenção secundária após intervenção coronária percutânea (ICP) é fundamental para melhorar a sobrevida livre de eventos e consiste principalmente no controle de fatores de risco. Analisou-se a prevenção secundária de pacientes de alto risco, incluídos prospectivamente no estudo Sequence Variation in Platelet Aggregation in Response to Clopidogrel and aspirin (SPARC). Métodos: Foram arrolados 187 pacientes consecutivos entre dezembro de 2009 e fevereiro de 2011, tratados por ICP com stent e avaliados em retornos ambulatoriais de 30 dias, três meses, seis meses, e 12 meses quanto ao controle de hipertensão arterial, disglicemia, dislipidemia e tabagismo, e medidas terapêuticas respectivas. Resultados: Houve aumento significativo de pacientes com controle pressórico $(29 \% ; \mathrm{P}=0,02)$, que cessaram tabagismo $(18 \% ; \mathrm{P}=$ $0,003)$, e que receberam hipolipemiantes $(19 \% ; \mathrm{P}<0,0001)$ entre a internação para ICP e o primeiro retorno após o

\footnotetext{
Resident physician in Hemodynamic and Interventional Cardiology of Hospital das Clínicas da Faculdade de Medicina de Ribeirão Preto da Universidade de São Paulo. Ribeirão Preto, SP, Brazil.

2 Full professor. Director of the Hemodynamic and Interventional Cardiology Unit of Hospital das Clínicas da Faculdade de Medicina de Ribeirão Preto da Universidade de São Paulo. Ribeirão Preto, SP, Brazil.

Resident physician in Hemodynamic and Pediatric Interventional Cardiology of Hospital das Clínicas da Faculdade de Medicina de Ribeirão Preto da Universidade de São Paulo. Ribeirão Preto, SP, Brazil. ${ }^{4}$ Doctor. Biomedical physician, Faculdade de Filosofia Ciências e Letras de Ribeirão Preto da Universidade de São Paulo. Ribeirão Preto, SP, Brazil.

${ }^{5}$ Cardiologist physician, assistant at the Hemodynamic and Interventional Cardiology Unit of Hospital das Clínicas da Faculdade de Medicina de Ribeirão Preto da Universidade de São Paulo. Ribeirão Preto, SP, Brazil. ${ }^{6}$ Assistant physician at the Hemodynamic and Interventional Cardiology Unit of Hospital das Clínicas da Faculdade de Medicina de Ribeirão Preto da Universidade de São Paulo. Ribeirão Preto, SP, Brazil.

7 Doctor. Assistant physician at the Hemodynamic and Interventional Cardiology Unit of Hospital das Clínicas da Faculdade de Medicina de Ribeirão Preto da Universidade de São Paulo. Ribeirão Preto, SP, Brazil.
}

\begin{abstract}
${ }^{8}$ Assistant physician at the Hemodynamic and Interventional Cardiology Unit of Hospital das Clínicas da Faculdade de Medicina de Ribeirão Preto da Universidade de São Paulo. Ribeirão Preto, SP, Brazil.

${ }^{9}$ Coordinator of Clinical Research of the Cardiology Division of Hospital das Clínicas da Faculdade de Medicina de Ribeirão Preto da Universidade de São Paulo. Ribeirão Preto, SP, Brazil.

${ }^{10}$ Biomedical physician. Laboratory technician at the Cardiology Division of Hospital das Clínicas da Faculdade de Medicina de Ribeirão Preto da Universidade de São Paulo. Ribeirão Preto, SP, Brazil.

11 Hematologist. Assistant physician at Hemocenter and Hematology Laboratory of Hospital das Clínicas da Faculdade de Medicina de Ribeirão Preto da Universidade de São Paulo. Ribeirão Preto, SP, Brazil. 12 Doctor. Resident physician in the Hemodynamic and Interventional Cardiology of Real e Benemérita Associação Portuguesa de Beneficência de São Paulo. São Paulo, SP, Brazil.
\end{abstract}

Correspondence to: José Antonio Marin-Neto. Hospital das Clínicas da Faculdade de Medicina de Ribeirão Preto da Universidade de São Paulo - Divisão de Cardiologia - Av. Bandeirantes, 3.900 - 2o andar Campus Universitário da USP - Bairro Monte Alegre - Ribeirão Preto, SP, Brazil - CEP 14048-900

E-mail: marin_neto@yahoo.com

Received on: 3/18/2013 • Accepted on: 5/21/2013 
control drugs and achievement of therapeutic goals. This study identifies a relevant opportunity window for risk factor control at the index admission, when substantial gains are observed and maintained. However, it also shows further efforts are required to expand the benefit of secondary prevention in the middle-term follow-up of patients treated by $\mathrm{PCl}$.

DESCRIPTORS: Coronary artery disease. Angioplasty. Stents. Risk factors. Disease prevention.

A ccording to data from the Department of Informatics of the Brazilian Unified Health System (Departamento de Informática do Sistema Único de Saúde - DATASUS), in the year 2012, cardiovascular diseases were the main cause of morbidity after the age of 39 years. In that year, they represented $20.95 \%$ of $1,004,004$ hospitalizations at this age range. ${ }^{1}$ Cardiovascular diseases are also the leading cause of mortality in this same age group, with 641,424 deaths, representing $30.84 \%$ of the deaths recorded in the DATASUS information system in $2010 .^{2}$

Percutaneous coronary intervention $(\mathrm{PCl})$ has become the most used treatment in the spectrum of coronary heart disease, surpassing coronary artery bypass graft (CABG) surgery, wether to relieve angina symptoms, to improve quality of life, or to decrease mortality in different clinical contexts. ${ }^{3}$ In this context, there are patients with severe cardiovascular dysfunction due to the presence of coronary atherosclerotic disease and multiple associated risk factors. The secondary prevention in these patients, after $\mathrm{PCl}$ treatment, becomes critically necessary to reduce subsequent adverse cardiovascular events, requiring changes in lifestyle and control of risk factors with behavioral measures and medication. ${ }^{4}$ However, the integration of preventive measures in daily clinical practice is still poor, ${ }^{5}$ and the discontinuation of prescribed medications is common after acute events; ${ }^{6,7}$ moreover, it is very difficult to implement lifestyle changes.

The aim of this study was to evaluate the short- and mid-term control of risk factors in patients undergoing $\mathrm{PCl}$. These patients were prospectively included in the single-center research project Sequence variation in Platelet Aggregation in Response to Clopidogrel and aspirin (SPARC), which investigates platelet aggregation and its determinant genes in a cohort treated by $\mathrm{PCl}$, and is in its final phase of follow-up. procedimento. Esse melhora do controle de fatores de risco refletiu-se em redução do escore de risco de Framingham médio observado no mesmo período (9,9\%; $P<0,0001)$. Durante seguimento de até 12 meses o ganho atingido na internação para ICP se manteve para todos os fatores de risco. Conclusões: Observou-se efeito importante relativamente à internação índice para ICP, com aumento da prescrição de medicamentos para controle de fatores de risco e alcance de metas. Esse estudo identifica relevante janela de oportunidade para priorização do controle de fatores de risco na internação inicial, quando expressivos são observados e mantidos. Mas também explicita que esforços adicionais são necessários para expandir o benefício da prevenção secundária no seguimento a médio prazo de pacientes tratados por ICP.

DESCRITORES: Doença da artéria coronariana. Angioplastia. Stents. Fatores de risco. Prevenção de doenças.

\section{METHODS}

SPARC is a single-center study that enrolled consecutive patients between December of 2009 and February of 2011, who underwent PCl with stenting and signed an informed consent. Patients were excluded when they were not treated with dual antiplatelet therapy with acetylsalicylic acid (ASA) and clopidogrel, as well as those aged $<18$ years. The study was approved by the local and national ethics committees (CAAE. 0153.0.004.000-09).

Patients used a loading dose of clopidogrel of 300 $\mathrm{mg}$ six to 12 hours before the procedure. The use of clopidogrel continued for at least 30 days after the $\mathrm{PCl}$. In cases where drug-eluting stents (DES) were used, the use of clopidogrel continued for at least 12 months. ${ }^{8}$ Baseline clinical and demographic characteristics are shown as means and standard deviations for continuous variables and as percentages for discrete variables.

At the follow-up visits after 30 days, three months, six months, and 12 months, medication prescriptions and risk factor control were evaluated. The three-month follow-up could be cancelled at the discretion of the attending physician in cases of less complexity. If there was loss to follow-up, a telephone contact was made to substitute the 12-month consultation. Loss to follow-up was defined as patients who could not be contacted at the last consultation, either in person or by phone.

Data regarding the presence of factors risk for atherosclerosis (systemic arterial hypertension, dyslipidemia, dysglycemia, and smoking) and changes in prescription to control these risk factors were obtained during follow-up visits at specific outpatient clinics for patients treated with $\mathrm{PCl}$ at the institution. For secondary prevention, the BP goal was defined as systemic blood pressure $<130 / 80 \mathrm{mmHg} ;{ }^{9}$ glycemic goal was defined as fasting glucose $<140 \mathrm{mg} / \mathrm{dL}$ and glycated 
hemoglobin $<7 \%$; ${ }^{10}$ the acceptable low-density lipoprotein cholesterol (LDL - cholesterol) goal was defined as LDL-cholesterol $<100 \mathrm{mg} / \mathrm{dL} .^{11}$

The use of the following medications was recorded at enrollment and at each follow-up consultation: ASA, clopidogrel, statins, diuretics, beta-blockers, calciumchannel blockers, angiotensin-converting enzyme inhibitors, angiotensin receptor blockers II, nitrates, proton-pump inhibitors (omeprazole and similar drugs), and hypoglycemiants. To calculate the Framingham risk score (FRS) at enrollment, the lipid assessment used was that performed 30 days after $\mathrm{PCl}$, due to changes in the lipid profile during acute coronary syndrome. ${ }^{12,13}$

Statistical analysis was performed with the program Stata 12.0 (Stata Corp. - College Station, USA). The achievement of goals and the prescription of medications were evaluated by analyzing the effect of the index hospitalization, the difference between admission and the first follow-up, and the effect of clinical follow-up, comparing trends between the first and last follow-up visits. Analysis of variance was used to compare the patients according to the follow-up visits and to assess whether the therapeutic goals were achieved. The comparison of proportions between two follow-ups was tested using the McNemar test, and the trend of proportions during the follow-ups was tested using the chi-squared test ${ }^{2}$ for trends. ${ }^{14}$ The comparison of the FRS (non-parametric variable) was performed by Wilcoxon paired test. Statistical significance was set at $\mathrm{P}<0.05$.

The differences between patients who achieved the therapeutic goals and those who did not were also evaluated. The differences analyzed in this last assessment were: age, body mass index, gender, clinical indication, prior $\mathrm{PCl}$, family history, peripheral arterial disease, prior $\mathrm{CABG}$, prior myocardial infarction, and number of affected vessels. In this case, Bonferroni correction for multiple comparisons was used $(P<0.005)$. Analysis of the cardiac events was not performed, as the study was not designed to be able to compare these subgroups.

\section{RESULTS}

A total of 197 patients were enrolled during the study period. Seven of these patients (3.6\%) did not undergo $\mathrm{PCl}$ with stent implantation, and three patients withdrew consent to participate after recruitment; thus, 187 patients remained in the study.

The patients' mean age was 60.8 years, $68.4 \%$ (130) were males and $82.1 \%$ (151) considered themselves whites. Baseline characteristics and $\mathrm{PCl}$ data are shown in Table 1. Patients were followed after the PCl through standardized follow-up visits after 30 days, three, six, and 12 months. Attendance of patients at these followups was $95 \%, 56 \%, 86 \%$, and $92 \%$, respectively. A total of $7.5 \%$ of patients (14) were lost to follow-up. The loss to follow up occurred after the first follow-up
TABLE 1

Baseline data and characteristics of the percutaneous coronary intervention of patients enrolled in the study

\begin{tabular}{|c|c|}
\hline Variable & \pm \\
\hline Age, years & $60.8 \pm 9.7$ \\
\hline Male gender, \% & 68.4 \\
\hline White, \% & 82.1 \\
\hline Body mass índex, $\mathrm{Kg} / \mathrm{m}^{2}$ & $27.3 \pm 4.9$ \\
\hline Previous infarction, $\%$ & 18.8 \\
\hline $\begin{array}{l}\text { Previous percutaneous coronary } \\
\text { intervention, } \%\end{array}$ & 10.3 \\
\hline $\begin{array}{l}\text { Previous coronary artery bypass graft } \\
\text { surgery, \% }\end{array}$ & 4.9 \\
\hline Peripheral arterial disease, $\%$ & 4.3 \\
\hline Arterial hypertension, \% & 89.9 \\
\hline Dysglycaemia, \% & 40.6 \\
\hline Dyslipidaemia, \% & 73.3 \\
\hline Current smoking, \% & 40.5 \\
\hline $\begin{array}{l}\text { Family history of coronary artery } \\
\text { disease, } \%\end{array}$ & 36.2 \\
\hline \multicolumn{2}{|l|}{ Clinical presentation, $\%$} \\
\hline $\begin{array}{l}\text { Myocardial infarction with ST-segment } \\
\text { elevation }\end{array}$ & 24.6 \\
\hline $\begin{array}{l}\text { Myocardial infarction without } \\
\text { ST-segment elevation or high-risk } \\
\text { unstable angina }\end{array}$ & 28.9 \\
\hline Stable angina & 42.8 \\
\hline Silent ischaemia & 3.7 \\
\hline Multivessel, \% & 50.3 \\
\hline \multicolumn{2}{|l|}{ Treated vessel, \% } \\
\hline Left coronary trunk & 0.7 \\
\hline Left anterior descending artery & 50 \\
\hline Left circumflex artery & 21.1 \\
\hline Right coronary artery & 36.1 \\
\hline Saphenous venous graft & 0.7 \\
\hline Multivessel treatment, \% & 10.3 \\
\hline Drug-eluting stents, \% & 15.6 \\
\hline
\end{tabular}

in $1.1 \%$, after the second follow-up in $1.6 \%$, and after the third follow-up in $4.8 \%$ of patients. In 12 patients $(6.4 \%)$, the last consultation was performed only by telephone contact.

To evaluate the effect of treatment conducted in the outpatient clinic, data were collected on medication use and controllable risk factors, notably hypertension, dysglycemia, dyslipidemia, and smoking status. The 
assessment was separated regarding the effect of the index hospitalization and outpatient follow-up, and regarding differences between the patients who had success in reaching a goal versus patients who failed to do so.

The baseline prevalence of patients diagnosed with systemic arterial hypertension was $89.9 \%$, with a mean of 1.8 antihypertensive medications. At admission, $49.1 \%$ of patients had controlled blood pressure, and at the first follow-up, $63.3 \%$, representing a significant increase of $29 \%(P=0.02)$. Table 2 shows the evolution of medication prescription and achievement of BP goal according to the follow-up visits. There was no difference in BP goal achievement between the first and last follow-ups $(P=0.3)$.

The analysis of variance indicates that patients who did not achieve their BP goal were prescribed more antihypertensive medications when compared to those who did achieve their BP goal $(P=0.02)$, with interaction with the date of follow-up $(\mathrm{P}=0.049)$. Considering the interaction in the statistical model, the difference in prescription per follow-up consultation was calculated, which was statistically significant at the six-month and 12-month follow-ups.

The prevalence of dysglycemia at study enrollment was $40.6 \% ; 60.5 \%$ of these patients received drug treatment with oral hypoglycemiants or insulin. At the first follow-up, the use of oral hypoglycemiants or insulin in dysglycemic patients presented a nonsignificant increase to $69.9 \%(P=0.2)$. Glycemia was not measured at the index hospitalization. Table 3 shows the glycemic control rate according to each follow-up and the percentage of use of hypoglycemiants of each subgroup. There was no difference in the achievement of therapeutic goals between the first and last follow-ups $(\mathrm{P}=0.8)$.

TABLE 2

Achievement of blood pressure (BP) goal according to follow-up visit and number of antihypertensive drugs per patient

\begin{tabular}{lcccccccc}
\hline & \multicolumn{2}{c}{$\mathbf{2 0}$ days } & \multicolumn{2}{c}{ 3 months } & \multicolumn{2}{c}{$\mathbf{6}$ months } & \multicolumn{1}{c}{$\mathbf{1 2}$ months } \\
\cline { 2 - 8 } Follow-up consultation & Yes & No & Yes & No & Yes & No & Yes & No \\
\hline Achievement of BP goal & 63.3 & 36.7 & 58.4 & 41.6 & 54.7 & 45.3 & 60.7 & 39.3 \\
Antihypertensives per patient & 2.2 & 2.2 & 2.3 & 2.3 & 2.3 & 2.6 & 2.2 & 2.6 \\
ANOVA $(p)$ & \multicolumn{2}{c}{0.8884} & 0.7745 & 0.0236 & 0.0026 \\
\hline
\end{tabular}

BP, blood pressure; ANOVA, analysis of variance.

TABLE 3

Achievement of glycemic goal in patients with dysglycemia according to follow-up visit and drug treatment

\begin{tabular}{|c|c|c|c|c|c|c|c|c|}
\hline \multirow[b]{2}{*}{ Follow-up consultation } & \multicolumn{2}{|c|}{30 days } & \multicolumn{2}{|c|}{3 months } & \multicolumn{2}{|c|}{6 months } & \multicolumn{2}{|c|}{12 months } \\
\hline & Yes & No & Yes & No & Yes & No & Yes & No \\
\hline $\begin{array}{l}\text { Fasting glycemia }<140 \mathrm{mg} / \mathrm{dL} \text { or } \mathrm{HbA} 1 \mathrm{c}< \\
7 \%, \%\end{array}$ & 57.7 & 42.3 & 59.1 & 40.9 & 56.8 & 43.2 & 53.2 & 43.8 \\
\hline Medications, \% & 80 & 50 & 69.2 & 55.6 & 80 & 63.2 & 84 & 54.6 \\
\hline
\end{tabular}

TABLE 4

Achievement of LDL-cholesterol goal according to follow-up visit and statin treatment

\begin{tabular}{lccccccccc}
\hline & \multicolumn{2}{c}{30 days } & \multicolumn{2}{c}{3 months } & \multicolumn{3}{c}{$\mathbf{6}$ months } & \multicolumn{1}{c}{$\mathbf{1 2}$ months } \\
\cline { 2 - 10 } Follow-up consultation & Yes & No & Yes & No & Yes & No & Yes & No \\
\hline LDL-cholesterol < $100 \mathrm{mg} / \mathrm{dL}, \%$ & 60.7 & 39.3 & 61.7 & 38.3 & 64.4 & 35.6 & 67 & 33 \\
Statin use, \% & 97.1 & 86.4 & 89.7 & 83.3 & 96.6 & 96.9 & 94 & 97 \\
\hline LDL-cholesterol, low-density lipoprotein cholesterol. & & & & & & & & \\
\hline
\end{tabular}


The analysis of variance shows higher prescription of oral hypoglycemiants and insulin among patients that reached the goal compared to those that did not $(P=0.004)$, with no significant interactions regarding follow-ups.

The rate of patients who achieved the LDL-cholesterol goal is shown in Table 4; 60.7\% achieved it at the first follow-up consultation. There is a non-significant trend of increase to $67 \%$, in the last follow-up consultation ( $P$ $=0.5)$. Upon study enrollment, $76.6 \%$ of the patients were prescribed statins, which soon increased to $91.5 \%$ in the first follow-up, representing a significant increase of $19 \%(P<0.0001)$. The rate of statin use did not vary with the follow-ups $(P=0.6)$. Among patients who did not reach the goal, there was a significant increase in statin prescription $(\mathrm{P}=0.045)$ without a corresponding significant decrease in the number of patients who did not reach the goal.

Table 5 shows the prevalence of smoking at the 30-day and 12-month follow-ups. In light of the definition used in the study, which only considers a patient an ex-smoker when he/she has ceased smoking for least 12 months, the prevalence of smoking at the 30-day, three-month, and six-month follow-ups was the same as those at the study enrollment. However, it was observed that, at the 12-month follow-up, there was a decrease of $18 \%(P=0.003)$ in the number of smokers; this reduction was significant compared to the initial prevalence of the study.

Comparisons were performed between the subgroups of patients who achieved the goals and those who did not. There were no significant differences between the subgroups of patients who achieved the BP, glycemia, and smoking cessation goals and those who did not. Patients who achieved the LDL-cholesterol goal, compared to those who did not, were mostly males (49.6\% vs. 26.7\%; P = 0.003) and entered the study with divergent indications for $\mathrm{PCl}(\mathrm{P}<0.001)$; they had more diagnoses of myocardial infarction with ST-segment elevation (38\% vs. $14.8 \%$ ), and less of stable angina (29.1\% vs. $52.8 \%)$.

The FRS was used to summarize the several risk factors controlled per patient in a single value. The patients' mean FRS was $14.2 \pm 6.4 \%$ at study enrollment , and $12.8 \pm 6.1 \%$ at the 30-day follow-up. Thus, a significant relative decrease of $9.9 \%(\mathrm{P}<0.0001)$ was

TABLE 5

Prevalence of smoking during follow-up visits

\begin{tabular}{lcc}
\hline Follow-up consultation & 30 days & 12 months \\
\hline Current smoker, \% & 42.2 & 34.6 \\
Ex-smoker (> 1 year), \% & 28.7 & 36.2 \\
Never smoked, \% & 29.2 & 29.2 \\
\hline
\end{tabular}

observed. There was no difference between the FRS at the 30-day and at the 12-month follow-up, which was $12.3 \% \pm 6.3 \%$.

\section{DISCUSSION}

The control of risk factors for cardiovascular disease and complications is complex, and demand resources and exhaustive efforts. In spite of abundant scientific evidence demonstrating its benefits in multiple clinical settings, integration of strategies for actual effectiveness in daily clinical practice remains quite inadequate. ${ }^{5}$

This study demonstrated a markedly positive effect associated with hospitalization for index $\mathrm{PCI}$, increased prescription of medications indicated to control risk factors, achievement of goals, and decrease in smoking, as previously reported..$^{15}$ Nevertheless, at the time of the $\mathrm{PCl}$, only $50 \%$ of patients had blood pressure within the desired range. This increased to $63 \%$ at the first follow-up. Smoking cessation, which was significant, representing $18 \%$ of patients, can be attributed temporally to the hospital, as patients are considered ex-smokers only after smoking cessation for at least 12 months. Considered a risk factor difficult to control, smoking cessation interconnects structured biopsychosocial factors, such as the habit of smoking and its associated practices, nicotine withdrawal syndrome, and the pleasure derived from this substance. ${ }^{16}$ These characteristics are factors that place the chance of success at the first cessation attempt below $10 \% .{ }^{17}$ Additionally, there was an increase in the proportion of patients who achieved glycemic and LDL-cholesterol goals, although at non-significant statistical levels.

During follow-up, the essential effect of the outpatient visits was to maintain the gains obtained at the index hospitalization. There was no variation in the rates of goal achievement during the follow-ups. There was an increased prescription of antihypertensive drugs and statins to patients who did not achieve their goals compared to those who did. This fact raises questions regarding patient's adherence to medications and recommended lifestyle changes. ${ }^{6}$ Considering that the patients treated at the outpatient clinic of this institution need and can make use of government programs for acquisition and supply of high-cost medications, free of charge, it is hypothesized that another barrier to the use of these drugs can result from excessive bureaucracy.

In the case of oral hypoglycemiants, an increase in the number of patients who achieved their goals was not observed, nor an increase in the prescription of oral hypoglycemiants or insulin. This may reflect not only the intrinsic difficulty of patients to follow specific behavioral measures for better control of dysglycemia, but also the occurrence of failures in nutritional counselling and physical activity. ${ }^{18}$ It is important to note that, in this study, the initial diagnosis of dysglycemia was based on the use of oral hypoglycemiants or insulin at 
the time of the $\mathrm{PCl}$, while the levels of fasting glucose and $\mathrm{HbA} 1 \mathrm{c}$ were also measured only at the follow-ups. Therefore, the initial high rate of patients with dysglycemia must reflect the heterogeneous composition of this group of patients, and not only of patients with an established diagnosis of diabetes mellitus.

Regarding the cardiovascular risk factors assessed in the study, no differences were observed between groups of patients who achieved or did not achieve the goals established to control those factors, except for the comparison of patients who achieved the LDLcholesterol goal versus those who did not. It should be noted that this subgroup of patients had a higher rate of $\mathrm{PCl}$ indication, due to acute myocardial infarction and lower rate of $\mathrm{PCl}$ indication due to stable angina. In fact, in general, at the 30-day follow-up, the mean LDL-cholesterol of patients who suffered myocardial infarction with ST-segment elevation was $83.7 \pm 3.7$ $\mathrm{mg} / \mathrm{dL}$, significantly lower than that of patients who had a diagnosis of stable angina, with $107 \pm 4.7 \mathrm{mg} / \mathrm{dL}(\mathrm{P}$ $=0.001)$. The effect of the reduction in apolipoprotein levels usually occurs in the first days after the infarction, and is not expected in subsequent measurements of cholesterol levels 30 days after the event. It can be assumed that, due to the initial severity of the event, these patients became more motivated regarding the treatment than patients with $\mathrm{PCl}$ indicated due to stable angina. In this context, is interesting to observe that incremental programs of secondary prevention stimulus after acute myocardial infarction, such as assistance through telephone contact, did not result in clinical gain nor appear to be cost-effective, compared with the usual preventive program. ${ }^{19}$

In this study, a relative decrease of $10 \%$ was observed in FRS between enrollments and at the 30-day follow-up, and its maintenance at subsequent follow-ups. Since the FRS includes in its calculation the risk factors evaluated in this study, despite having been created to assess the risk of primary cardiac events, it is suitable for the present context, as it allows for the use of a single value to represent all the preventive efforts performed. This fact not only demonstrates the importance of the index treatment, but also that there was no subsequent score variation during outpatient follow-up.

The increased survival, reduction of other severe adverse events, and quality of life improvement are not restricted to the success of percutaneous treatment in itself. In contrast, such results, if achieved, also reflect the effect of good quality and periodic medical follow-up in an attempt to overcome the difficulties inherent to the recommendations, changes in lifestyle, and adherence to the prescribed medications. In patients treated with $\mathrm{PCl}$, the increase in the achievement of goals related to risk factor control is expected when assistance is obtained from specific support groups provided by other health professionals, with introduction of specific treatments and multidisciplinary guidance, aiming at emphasizing the importance of medications. It is also noteworthy that, compared to the more traumatic procedure of CABG, patients treated with $\mathrm{PCl}$ appears to be more likely to adhere to secondary prevention, also due to greater adherence to medication use. ${ }^{20}$

\section{CONCLUSIONS}

The present study can be used as a basis to guide the initial measures of a secondary prevention program after $\mathrm{PCl}$, to generate hypotheses for implementing methods and therapies aimed at better control of risk factors, starting with its results as guides for current practices, as well as to serve as a historical control group in future clinical experimental groups for studies that measure effectiveness.

In essence, it identifies an excellent opportunity to prioritize the control of risk factors at the initial hospitalization related to the $\mathrm{PCl}$, when significant gains are observed and maintained. However, it can also be observed that additional efforts are needed to expand the benefit of secondary prevention in the middle-term follow-up of patients treated with $\mathrm{PCI}$.

\section{CONFLICTS OF INTEREST}

The authors declare no conflicts of interest.

\section{REFERENCES}

1. Brasil. Ministério da Saúde. DATASUS. Sistema de Informações Hospitalares do SUS. Morbidade hospitalar do SUS [Internet]. Brasília; 2012 [citado 2013 maio 5]. Disponível em: http:// tabnet.datasus.gov.br/cgi/sih/midescr.htm

2. Brasil. Ministério da Saúde. DATASUS. Sistema de Informações sobre Mortalidade. Mortalidade hospitalar do SUS [Internet]. Brasília; 2010 [citado 2013 maio 8]. Disponível em: http:// tabnet.datasus.gov.br/cgi/sih/midescr.htm

3. Piegas LS, Haddad N. Intervenção coronariana percutânea no Brasil: resultados do Sistema Único de Saúde. Arq Bras Cardiol. 2011;96(4):317-24.

4. Clark AM, Hartling L, Vandermeer B, McAlister FA. Metaanalysis: secondary prevention programs for patients with coronary artery disease. Ann Intern Med. 2005;143(9):659-72.

5. Kotseva K, Wood D, De Backer G, De Bacquer D, Pyorala K, Keil U; EUROASPIRE Study Group. EUROASPIRE III: a survey on the lifestyle, risk factors and use of cardioprotective drug therapies in coronary patients from 22 European countries. Eur J Cardiovasc Prev Rehabil. 2009;16(2):121-37.

6. Eagle KA, Kline-Rogers E, Goodman SG, Gurfinkel EP, Avezum A, Flather MD, et al. Adherence to evidence-based therapies after discharge for acute coronary syndromes: an ongoing prospective, observational study. Am J Med. 2004;117(2):73-81.

7. Ho PM, Spertus JA, Masoudi FA, Reid KJ, Peterson ED, Magid DJ, et al. Impact of medication therapy discontinuation on mortality after myocardial infarction. Arch Intern Med. 2006; 166(17):1842-7.

8. Smith SC Jr, Feldman TE, Hirshfeld JW Jr, Jacobs AK, Kern MJ, King SB 3rd, et al. ACC/AHA/SCAI 2005 guideline update for percutaneous coronary intervention: a report of the American College of Cardiology/American Heart Association Task Force on Practice Guidelines (ACC/AHA/SCAI Writing Committee to Update the 2001 Guidelines for Percutaneous Coronary Intervention). J Am Coll Cardiol. 2006;47(1):e1-121. 
9. Sociedade Brasileira de Cardiologia; Sociedade Brasileira de Hipertensão; Sociedade Brasileira de Nefrologia. VI Diretrizes Brasileiras de Hipertensão. Arq Bras Cardiol. 2010;95(1 Supl 1): 1-51.

10. Turner RC, Cull CA, Frighi V, Holman RR. Glycemic control with diet, sulfonylurea, metformin, or insulin in patients with type 2 diabetes mellitus: progressive requirement for multiple therapies (UKPDS 49). UK Prospective Diabetes Study (UKPDS) Group. JAMA. 1999;281(21):2005-12.

11. Sposito AC, Caramelli B, Fonseca FAH, Bertolami MC, Afiune Neto A, Souza AD, et al. IV Diretriz Brasileira sobre Dislipidemias e Prevenção da Aterosclerose: Departamento de Aterosclerose da Sociedade Brasileira de Cardiologia. Arq Bras Cardiol. 2007;88:2-19.

12. Rosenson RS. Myocardial injury: the acute phase response and lipoprotein metabolism. J Am Coll Cardiol. 1993;22(3): 933-40.

13. Pfohl M, Schreiber I, Liebich HM, Haring HU, Hoffmeister HM. Upregulation of cholesterol synthesis after acute myocardial infarction--is cholesterol a positive acute phase reactant? Atherosclerosis. 1999;142(2):389-93.

14. Royston P. PTREND: Stata module for trend analysis for proportions. Secondary PTREND: Stata module [Internet]. 2012 [cited 2013 May 8]. Available from: http://econpapers.repec. org/software/bocbocode/s426101.htm
15. Griffo R, Ambrosetti M, Tramarin R, Fattirolli F, Temporelli PL, Vestri AR, et al. Effective secondary prevention through cardiac rehabilitation after coronary revascularization andpredictors of poor adherence to lifestyle modification and medication. Results of the ICAROS Survey. Int J Cardiol. 2012 May 8 [Epub ahead of print]

16. Marchini JF, Schmidt A. Prevenção primária da doença cardiovascular. In: Nobre F, editor. Cardiologia de consultório. Barueri (SP): Manole; 2011. p. 127-41.

17. Rigotti NA. Clinical practice. Treatment of tobacco use and dependence. N Engl J Med. 2002;346(7):506-12.

18. Executive summary: standards of medical care in diabetes-2013 Diabetes Care. 2013;36 Suppl 1:S4-10.

19. Turkstra E, Hawkes AL, Oldenburg B, Scuffham PA. Costeffectiveness of a coronary heart disease secondary prevention program in patients with myocardial infarction: results from a randomised controlled trial (ProActive Heart). BMC Cardiovasc Disord. 2013;13(1):33

20. Hlatky MA, Solomon MD, Shilane D, Leong TK, Brindis R, Go AS. Use of medications for secondary prevention after coronary bypass surgery compared with percutaneous coronary intervention. J Am Coll Cardiol. 2013;61(3):295-301. 